\section{IMAGE CHALLENGE}

\section{A 40-year-old man with bicuspid aortic valve and huge LV}

\section{CLINICAL INTRODUCTION}

A 40-year-old man presented to our institute with progressive exertional dyspnoea for 1 year. Bicuspid aortic valve (BAV) with mild-to-moderate aortic regurgitation (AR) was diagnosed in his childhood by echocardiography, but he declined follow-up afterwards. Physical examination revealed a grade 3/6 'to-and-fro' murmur at the third left intercostal space. Chest radiograph showed an extremely enlarged cardiac silhouette (figure 1A), and ECG displayed complete left bundle branch block with frequent premature ventricular contractions. Transthoracic echocardiography demonstrated an extremely enlarged LV with end diastolic volume of $472 \mathrm{~mL}$ and $\mathrm{EF}$ of $20 \%$ (see figure 1B, C and online supplementary video 1 ).

\section{QUESTION}

Based on these imaging and clinical findings, what is the most likely cause of the patient's AR?

A. Aortic dissection

B. Aortico-left ventricular tunnel

C. Avulsion of anterior cusp from aortic annulus

D. Ruptured paravalvular abscess

E. Ruptured sinus of Valsalva aneurysm

For the answer see page 1080
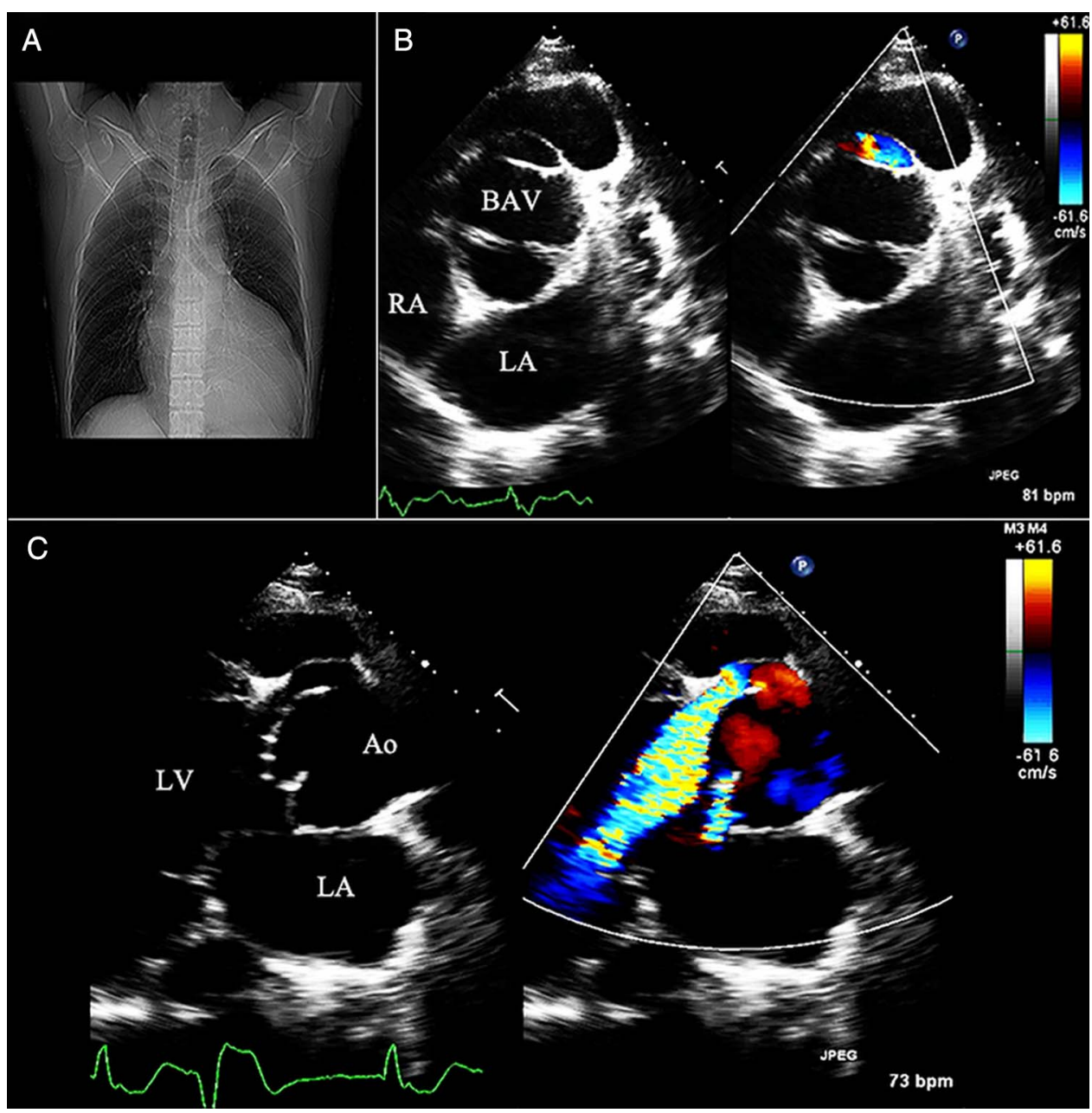

Figure 1 Chest radiograph (A), short axis (B) and long axis (C) transthoracic imaging of the aortic valve. BAV, bicuspid aortic valve. LA, left atrium; $\mathrm{RA}$, right atrium; Ao, aorta. 


\section{A 40-year-old man with bicuspid aortic valve and huge LV}

\section{From the question on page 1031}

\section{ANSWER: B}

The correct answer is aortico-left ventricular tunnel (ALVT). Echocardiography (figure 1B, C) and multislice CT angiography (figure 2A, B) revealed a tunnel-like structure with significant anterograde systolic and retrograde diastolic flow originating from the aortic root just above the level of the dilated aortic sinus and winding leftwards down into the LV, which was the signature feature of ALVT. ${ }^{2}$ The final diagnosis of type II ALVT, characterised as extracardiac aortic wall aneurysm of the tunnel with or without valvular distortion, was confirmed by surgical inspection (figure 2C), and the patient performed well after surgical closure of the tunnel. ${ }^{3}$

ALVT associated with BAV is an extremely rare condition. The coexistence of AR and BAV can frequently lead to diagnostic errors, confounding the rare malformation (the tunnel) with the more frequent one (valvular regurgitation caused by the BAV). Obviously, this patient was misdiagnosed as BAV with valvular regurgitation when he was a child, leading to treatment delay and clinical deterioration. In addition, the differential diagnosis for aortic root aneurysm and congestive heart failure in the setting of BAV should include aortic dissection and infective endocarditis. ${ }^{4}$ Aortic dissection would demonstrate a mobile intimal flap with the pattern of motion different from aortic wall, which was not present in the patient. Options like ruptured paravalvular abscess and avulsion of anterior cusp from the aortic annulus were not applicable, since no clinical clue suggesting infection or connective tissue diseases was found and the AR was no more than mild. The possibility of ruptured sinus of Valsalva aneurysm was also ruled out as the sinus wall was consistent and symmetrical in this patient without typical 'wind sock' appearance.

\section{Yongshi Wang, ${ }^{1,2}$ Lili Dong, ${ }^{1,2}$ Xianhong Shu ${ }^{1,2}$}

${ }^{1}$ Shanghai Institute of Medical Imaging, Zhongshan Hospital, Fudan University, Shanghai, China

${ }^{2}$ Shanghai Institute of Cardiovascular Diseases, Zhongshan Hospital, Fudan University, Shanghai, China
Correspondence to Dr Lili Dong, Shanghai Institute of Cardiovascular Diseases, Zhongshan Hospital, Fudan University; and Shanghai Institute of Medical Imaging, 180 Fenglin Road, Shanghai 200032, China; dong.lili@zs-hospital.sh.cn

Contributors YW and LD contributed to the manuscript writing. LD and XS contributed to the image collection.

Competing interests None.

Patient consent Obtained.

Provenance and peer review Not commissioned; externally peer reviewed.

- Additional material is published online only. To view please visit the journal online (http://dx.doi.org/10.1136/heartjnl-2014-306868).

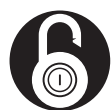

\section{OPEN ACCESS}

Open Access This is an Open Access article distributed in accordance with the Creative Commons Attribution Non Commercial (CC BY-NC 4.0) license, which permits others to distribute, remix, adapt, build upon this work non-commercially, and license their derivative works on different terms, provided the original work is properly cited and the use is non-commercial. See: http://creativecommons.org/ licenses/by-nc/4.0/

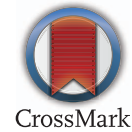

To cite Wang Y, Dong L, Shu X. Heart 2015;101:1080.

Received 28 December 2014

Revised 1 February 2015

Accepted 10 February 2015

Heart 2015;101:1080. doi:10.1136/heartjnl-2014-306868

\section{REFERENCES}

1 Konzag I, Wagner G, Zerkowski HR. Aorto-left ventricular tunnel. Heart 1999;82:225.

2 Martins JD, Sherwood MC, Mayer JE Jr, et al. Aortico-left ventricular tunnel: 35-year experience. J Am Coll Cardiol 2004:44:446-50.

3 Hovaguimian $\mathrm{H}$, Cobanoglu A, Starr A. Aortico-left ventricular tunnel: a clinical review and new surgical classification. Ann Thorac Surg 1988;45:106-12.

4 Fedak PW, Verma S, David TE, et al. Clinical and pathophysiological implications of a bicuspid aortic valve. Circulation 2002;106:900-4.

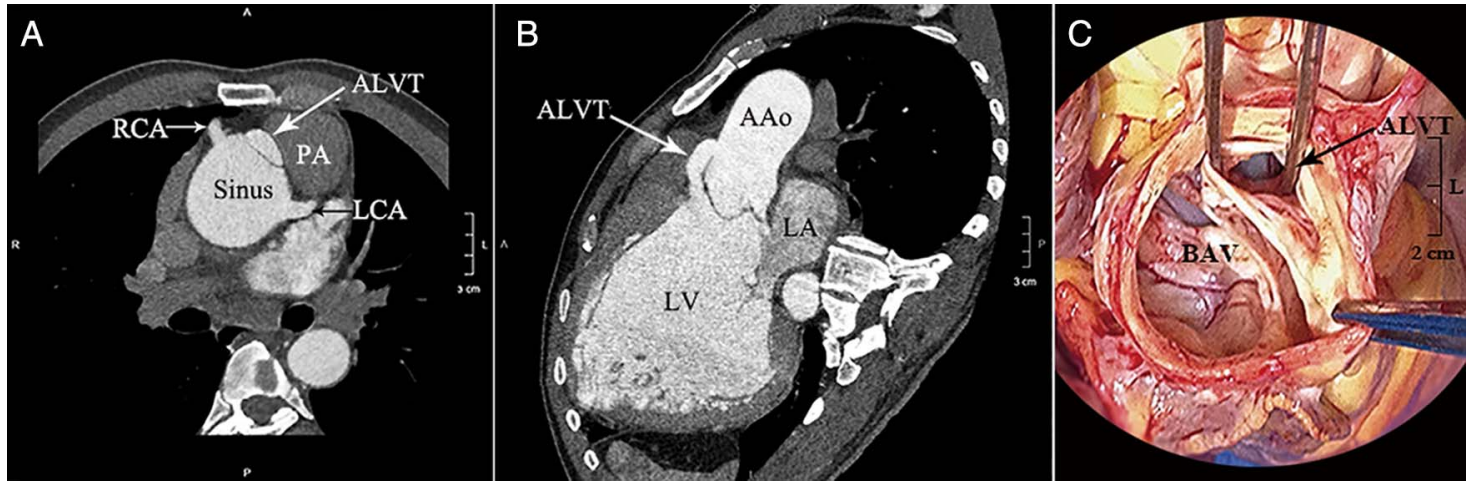

Figure 2 Multislice CT angiography demonstrated a tunnel-like structure originating from the aortic root just above the level of the aortic sinus and winding leftwards down into the LV (A and B). The diagnosis of type II aortico-left ventricular tunnel (ALVT) was confirmed by surgical inspection (C). BAV, bicuspid aortic valve. LA, left atrium; LCA, left coronary artery; RCA, right coronary artery; PA, pulmonary artery. AAo; ascending aorta. 